\title{
Mobile based Student Attendance Management System
}

\author{
Monika Singh \\ B.Tech. Scholar \\ Department of CSE, \\ S.I.E.T \\ Allahabad
}

\author{
Divya Tripathi \\ B.Tech. Scholar \\ Department of CSE, \\ S.I.E.T \\ Allahabad
}

\author{
Ashutosh Pandey \\ Assistant Professor \\ Department of CSE, \\ S.I.E.T \\ Allahabad
}

\author{
Rakesh Kumar Singh \\ Professor \\ Department of EC, S.I.E.T \\ Allahabad
}

\begin{abstract}
The main objective of this paper is to carry out some of the emerging technologies like mobile computing, Information and Communication Technology and advances in behavioural science studies to enhance and enriched the current educational system scenario, since the educational technology in India has been get modernizing in the recent past years due to the development and penetration of Information and Technology. The mobile based technology has been chosen for this study as well as for the project. The methodology of this work is to developed an android based mobile application attendance management system where attendance can be recorded via mobile devices using "php" and "MySQL" server .This developed software stores, retrieves and deliver the information about the student information such as present or absent through mobile device in the provided server database. The final result of this project are very useful for the educational organizations to keep ,track and maintain the database of students.
\end{abstract}

\section{Keywords}

Attendance, Educational, Admin, Information, Database, Web Server

\section{INTRODUCTION}

In the current scenario of various educational institutions to manage and maintaining student information is very tough task for any one. The whole academic record of the student information consist of monitoring their performance and progress changes periodically which is very huge workload on lecturers to handle and keep on updating the progress report of each and every student in against of their respective scheduled classes. The traditional way of taking attendance through the lecturers is a manually in a register book in which they are used to do a manual calculation to maintain monthly attendance database of the students. Such system takes so much time to generate record and many times its creates an error also as it follow manual traditional system. Apart from this error problems some time many more problems are generated like lost of attendance register book or manually fake data inserted through unknown recourses which are really not authorized for that work. In order to reduce all these problems and concern overcome through this problem, a smart mobile based application is generated to increase its efficiency as well as its security by sending all information about the students to the authorized web based admin panel server as it linked in the proposed mobile application. It is a beneficial step in every way for our future E-schools. It consist of five modules such as admin controlling, teachers authentication, student authentication,displaing digital register,submiting final report to the given admin web based server. This android based application used by the teacher to login and through its subject id and class id display the digital register for the particular class students and finally submit it to the authorized admin panel. As it already defined that the admin panel is totally web based secured web site which is authorized to make changes in any of the database of the students as well as the teachers.Therefore, it is crucial to reinforce the use of the mobile based attendance application to register system in order to improve the traditional process of recording and reporting the students attendance in the higher educational organizations.

\section{DRAWBACKS OR CONS OF THE CURRENT EXISTING SYSTEM}

2.1 Manually calculated maintenance of data

2.2 Suddenly searching for any type of related data is very difficult as well as it create mess over there.

2.3 It not provides the accurate data of attendance of students in the percentage calculation form.

2.4 Portability.

2.5 Losing of data problem can be occurred easily.

\section{OBJECTIVES}

To developed and design the android-based mobile attendance application for the management of attendance records in the educational organization. To implement the new technology development system to make it digitalized ,autherized,secured one in the given web server to kept it records as many years we want to kept it for its future use as per our need.

\section{METHODOLOGY}

This project is developed by using Android Studio, php and MySQL wamp server. It is divided into two phases. In the very first phase, feasibility study is conducted, requirement analysis is carried out to understand the need for the system and the necessary modules, such as admin module,registeration module, teacher modules. In the web based module is for the admin panel to control its all over activates like updating ,creation, deletion or any other database changes in the whole project by the admin and its also contains a teachers registration phase on website only through which they can generate a user id and password to login in the mobile based application which will be connected through this admin panel server. on the other hand the mobile based application will be totally used by the teacher to get logged in and by choosing their authorized register class id and the subject id they are able to display the digital register book on their smart mobiles onwards and submit it finally by cross checking it to the main authorized provided admin server. 


\section{MODULES DESCRIPTION}

\subsection{Administrator Module}

This module is used to login for administerator,it have whole rights to monitor and manage the entire project, through this module any new information can be easily inserted, updated, deleted or view.

\subsection{Teacher Module}

This module is used for the teachers to get register on website in respect to generate a user id and password through which they are able to logged in the smart mobile based attendance application to display the digital register book and submit the final data to the authorized web server of the admin panel.

\section{RESULTS AND DESCRIPTION}

In the following figures first of all the Fig-1=showing the home page of the web based server architectural view through php and MySQL, Fig-2=showing the admin login page, Fig$\mathbf{3}=$ showing the whole admin control panel, Fig-4=showing the new teacher registration page by the admin, Fig-5=showing the new class registration page by the admin, Fig-6=showing the new student registration page, Fig-7=showing the teachers registration page through teachers only to create the user id and password to get logged in app, Fig-8=showing the Welcome Screen of the proposed mobile based application, Fig-9=showing the login page for the registered teachers only, Fig-10=showing the combinational form page to select the particular class digital register book by entering valid group id and subject id, Fig-11=showing last digital register book on the mobile based application.

\subsection{Web based server architectural view}

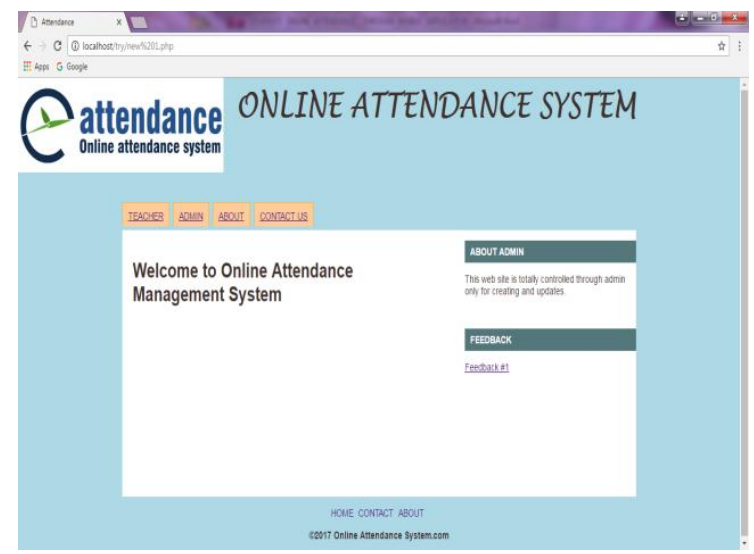

Figure-1=Home Page.

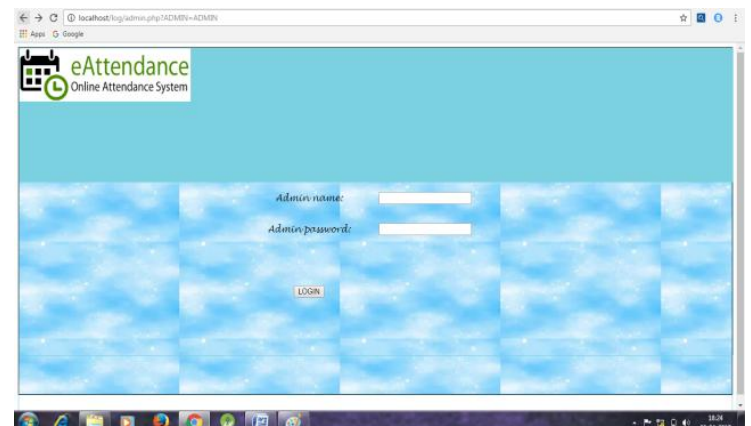

Figure-2=Admin login page.

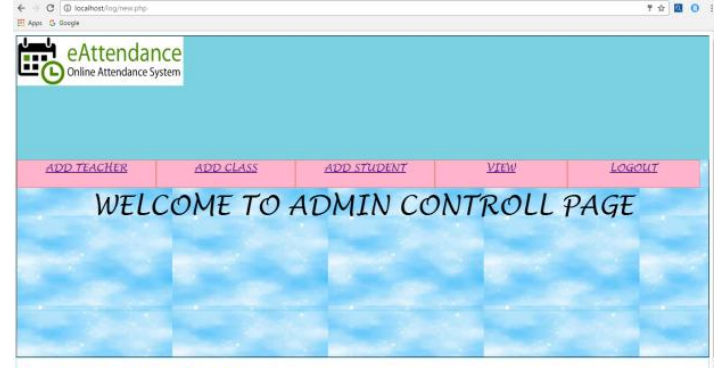

CEADOGR⿴囗十

Figure-3=Admin Control Panel.

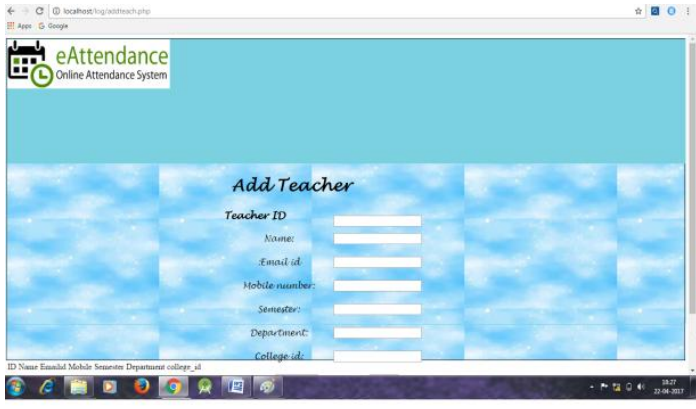

Figure-4=New Teacher registeration page.

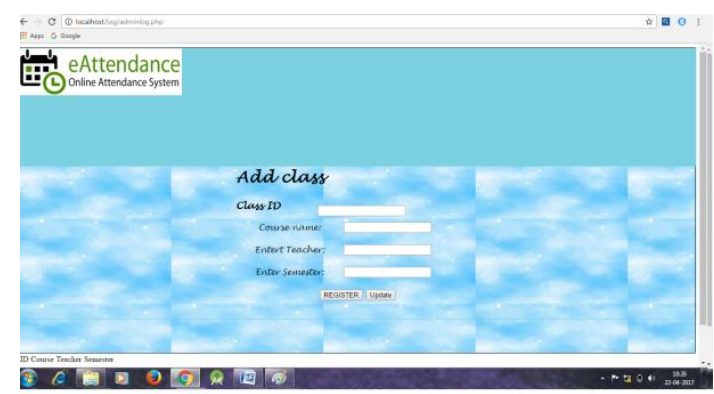

Figure-5=New Class or Course registration page.

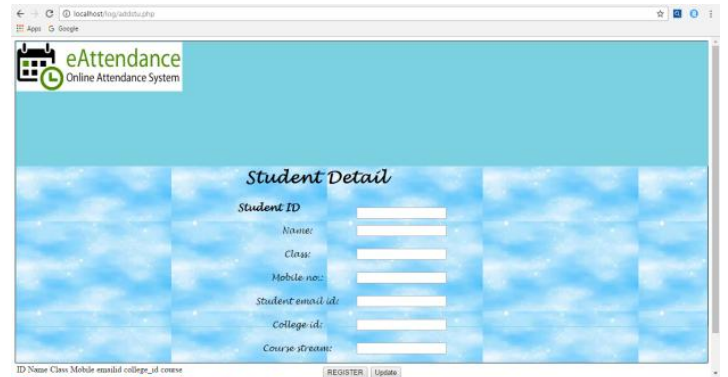

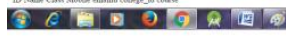

Figure-6=New Student registration page.

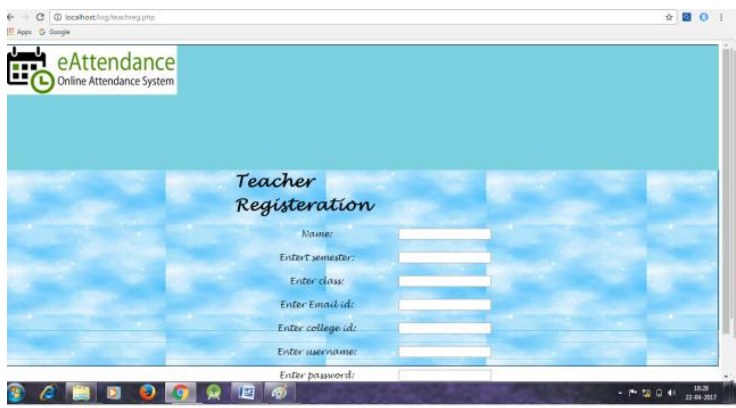

Figure-7=Teacher registration page to create login and password. 
6.2 Mobile Application based architectural view:-

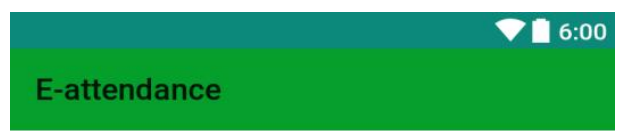

\section{E-Attendance}

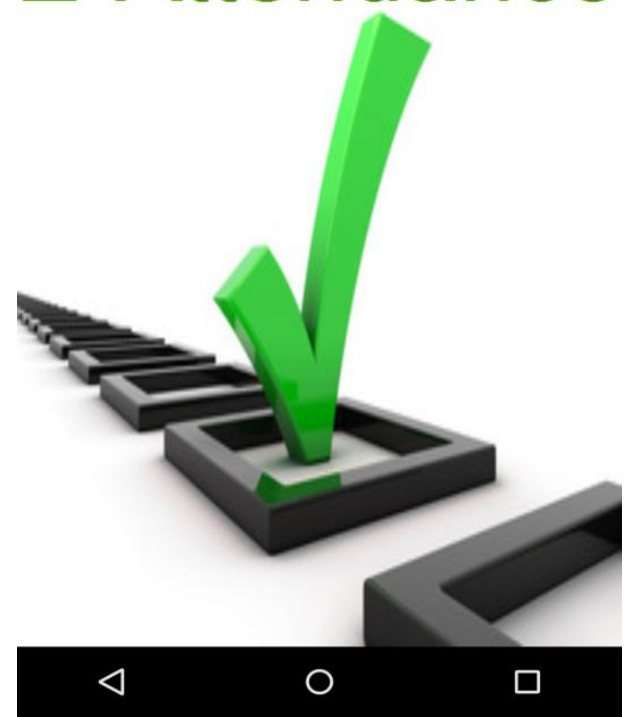

Figure-8=Welcome Screen.
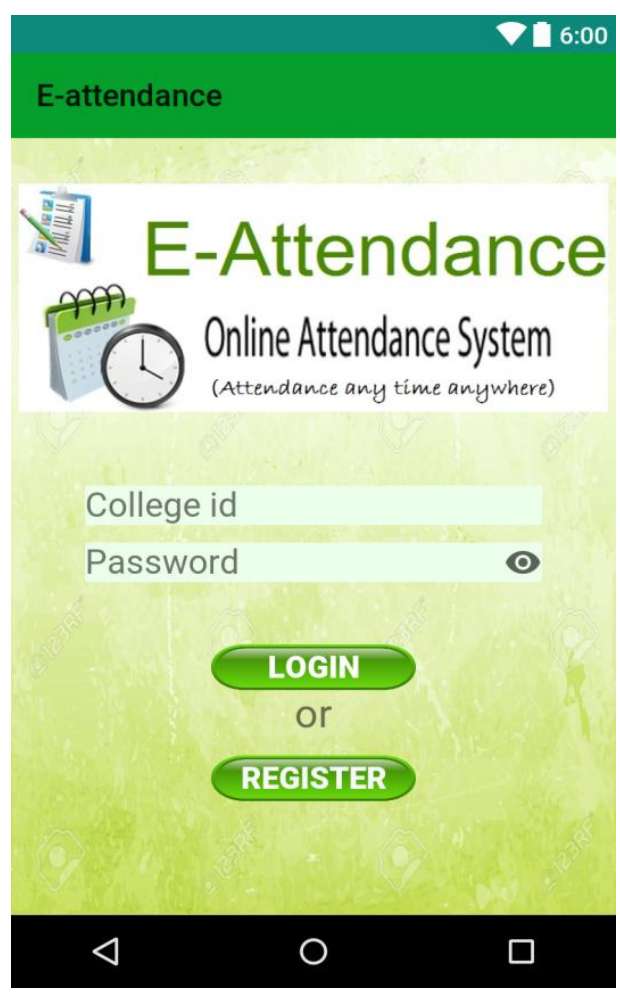

Figure-9=Login page.

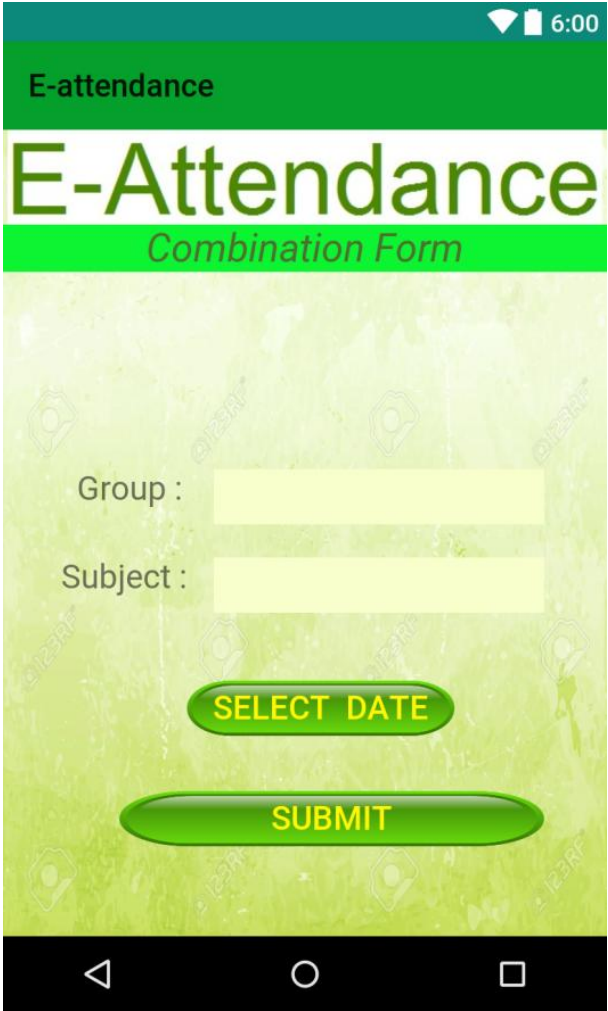

Figure-10=Combination form.

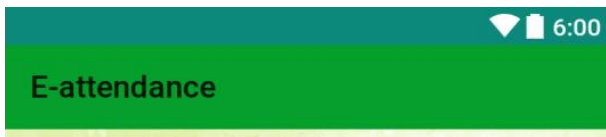

Attendance Date :

Subject :

Semester :

s no Student_id Student Name $\mathrm{OPO}$ A $\mathrm{P}$ เ

$\triangleleft$

○

$\square$

Figure-11=Digital Register Book. 


\section{CONCLUSION}

This whole work is to access the details about the student attendance information and generate a final reports. This project "Mobile Based Student Attendance Management System" is a collection of static and dynamic web based or mobile application based pages. This project provides an offer to the user to enter the data through their respective registration forms. It is very helpful for the teachers and admin to keep and maintain the information about the students easily. In future this work can be expanded to store the internal marks, semester marks, college events and college placement activities of the students to get minimized all stuffs at one place in a systematic way to import and export the data through the admin and authorized persons whenever it will be needed in future by the educational organization.

\section{ACKNOWLEDGEMENT}

We authors are grateful to our teachers, who support and helped us throughout our project and gave us all the possible knowledge and required data related to our project topic which we had required for preparing our project and paper presentation. They all encouraged us to take interest in android development and guided us through each step.

\section{REFERENCES}

[1] Mobile Phone Based Attendance System", by Shraddha S.Chawhan1, Mangesh P. Girhale2, Gunjan Mankar3, IOSRJournal of Computer Engineering (IOSRJCE) e-ISSN:2278-0661, p- ISSN: 2278-8727Volume 10, Issue 3 (Mar. -Apr. 2013), PP 48-50 www.iosrjournals.org.

[2] Component-Based Software Engineering" byIan Gorton, George T. Heineman, Ivica Crnković, Heinz W. Schmidt, Judith A. Stafford, Clemens Szyperski, Kurt Wallnau9th International Symposium, CBSE 2006, Västerås, Sweden, June 29 - July 1, 2006. Proceedings Volume 40632006ISBN: 978-3-540-35628-8
[3] A Proposed Android Based Mobile Application to Monitor Works at Remote Sites", byS. Sivasubramanian1, S. Sivasankaran2,S. Thiru Nirai Senthil3,IJSR International Journal of Science and Research ISSN (Online): 2319-7064 Volume 3 Issue 2, February 2014.

[4] S. Kadry and K. Smaili, "A Design and Implementation of a Wireless Iris Recognition Attendance Management System," Information Technology and Control Kaunas, Techbologija, vol. 36, no. 3, pp. 323-329, 2007.

[5] P. Simao, J. Fonseca, and V. Santos, "Time attendance system with multistation and wireless communications," in Proc. IEEE International Symposium on Consumer Electronics, 2008, pp. 1-4.

[6] Patel UA, Swaminarayan Priya R. Development of a Student Attendance Management System using RFID and Face Recognition: A Review. International Journal of Advance Research in Computer Science and Management Studies. 2014 Aug; 2(8):109-19

[7] Avinaash Ram SP, Albert Mayan J. Mobile Attendance Management and Employee Registration. ARPN Journal of Engineering and Applied Sciences. 2015 May; 10(8):3727-30.

[8] Mohammad SU, Allayear SM, Das NC, Talukder FA. A Location Based Time and Attendance System. International Journal of Computer Theory and Engineering. $2014 \mathrm{Feb}$; 6(1):36-8.

[9] Joshi R, Shete VV, Somani SB. Android Based Smart Learning and Attendance Management System. International Journal of Advanced Research in Computer and Communication Engineering. 2015 Jun; 4(6):256-60. 